\title{
Intravenous administration of adipose-derived stromal cells does not ameliorate bleomycin-induced lung injury in rats ${ }^{*}$
}

\author{
Masato Uji , Akira Nakada, Tatsuo Nakamura \\ Department of Bioartificial Organs, Institute for Frontier Medical Sciences, Kyoto University, Kyoto, Japan; \\ ${ }^{\#}$ Corresponding Author: m4959073@gmail.com, nakada@frontier.kyoto-u.ac.jp, nakamura@frontier.kyoto-u.ac.jp
}

Received 6 February 2013; revised 10 March 2013; accepted 8 April 2013

Copyright (C) 2013 Masato Uji et al. This is an open access article distributed under the Creative Commons Attribution License, which permits unrestricted use, distribution, and reproduction in any medium, provided the original work is properly cited.

\begin{abstract}
Background: Mesenchymal stromal cells (MSCs) have been studied intensively in regenerative medicine. Among MSCs, adipose tissue-derived stromal cells (ASCs) are relatively easy to obtain from a patient. Since ASCs are ideal candidates for use in the treatment of disease states including pulmonary fibrosis, we investigated whether intravenous injection of ASCs could exert a therapeutic effect against bleomycininduced lung injury in rats. Methods: Rats were intratracheally administered bleomycin, and one week later ASCs were isolated and cultured. Two weeks after bleomycin treatment ASCs or PBS (phosphate-buffered saline) were injected to the rats. Three or six weeks after bleomycin instillation, the total cell counts and their profile in bronchoalveolar lavage fluid (BALF) were measured, and a histological evaluation was semiquantitatively assessed for the injured lungs, followed by cell tracing. Results: The BALF cell counts and its profiles were not significantly different in the ASCs and PBS groups. Furthermore, ASC treatment led to no significant histological effect compared with the PBS treatment. Using a fluorescent cell tracer, it was noted that the ASCs homed to the injured lung areas, but some ASCs accumulated around
\end{abstract}

\footnotetext{
Author's Contribution: MU: performed animal experiments, histological evaluations and scoring, the statistical analyses, and wrote the manuscript. AN: performed animal experiments, histological evaluations and scoring, and participated in the analyses and writing. TN: conceived, supervised and coordinated the study. All authors have read and approved the submission of the manuscript, and that the manuscript has not been published and is not being considered for publication elsewhere in whole or in part in any language.

Conflicts of Interest: The authors declare that they have no competing interests.
}

scars, and scarcely migrated into the fibrotic areas. Conclusions: In the present study, the intravenous administration of ASCs could not reduce the severity of bleomycin-induced lung injury in a rat model. Although the ASC counts and passage numbers were suitable, the older age and fibrotic disease stage of the rats were likely responsible for the treatment failure.

Keywords: Adipose Tissue; Aged; Mesenchymal Stromal Cells; Migration; Pulmonary Fibrosis

\section{INTRODUCTION}

Idiopathic pulmonary fibrosis (IPF) is a refractory and lethal form of pulmonary fibrosis characterized by fibroblast proliferation, extracellular matrix deposition, and progressive lung scarring, and exhibits a histopathological pattern consistent with usual interstitial pneumonia (UIP) $[1,2]$. Despite extensive research and rapid expansion of scientific knowledge, the pathogenesis of IPF remains unclear. Recent data strongly suggest that the mechanisms driving IPF reflect abnormal, deregulated wound healing in response to multiple sites of ongoing alveolar epithelial injury, involving increased activity, and possibly exaggerated responses by a spectrum of proinflammatory and profibrogenic factors $[3,4]$. Most treatments, such as corticosteroids, and immunosuppressive, immunomodulatory, or antifibrotic agents, seek to suppress inflammation, but none has been proven to alter this process $[5,6]$.

Mesenchymal stromal cells (MSCs), of different cellular origins (umbilical cord, bone marrow, adipose tissue), represent one of the most challenging and promising areas of research in terms of novel therapeutic strategies. MSCs have recently been applied for the treatment 
of several chronic, incurable diseases [7,8]. Under certain circumstances, MSCs can differentiate into chondrocytes, myoblasts, endothelial cells, epithelial cells, and neurocytes [9]. Furthermore, MSCs have been observed to display immunomodulatory properties [10-13].

Adipose-derived stromal cells (ASCs) have been identified as an alternative source of bone marrow-derived MSCs (BMMSCs) because of their easy extraction, high content of MSCs and ex-vivo expandability. ASCs, similar to BMMSCs, not only possess the ability to self-renew and differentiate into various mesenchymal cell types, but also secrete significant levels of many potent growth factors and cytokines [14-16]. However, little information exists about the effects of ASCs treatment on bleomycin-induced lung injury. The purpose of this study was to examine whether ASC treatment could attenuate bleomycin-induced lung injury in rats.

\section{MATHELIALS AND METHODS}

\subsection{Bleomycin-Induced Lung Injury Model}

A total of $10 \mathrm{mg}$ bleomycin chloride (Nippon Kayaku, Japan) was dissolved in $1.0 \mathrm{ml}$ of sterile $0.9 \%$ saline (BLM). Male Wistar rats, aged more than 24 weeks and weighing from 370 to $540 \mathrm{~g}$ (Shimizu Laboratory Supply, Kyoto, Japan), were intratracheally administerd $1.0 \mathrm{ml}$ $\mathrm{BLM} / \mathrm{kg}$ or $1.0 \mathrm{ml}$ saline $/ \mathrm{kg}$ under anesthesia induced by an intraperitoneal injection of sodium pentobarbital (3 $\mathrm{mg} / 100 \mathrm{~g}$ body weight). The institutional animal care and use committee approved this study, and all experiments abided by the Principles of Laboratory Animal Care advocated by the Animal Experiment Committee of Kyoto University (2007).

\subsection{Isolation and Culture of Rat ASCs}

White adipose tissue (WAT) was collected under anesthesia induced by the intraperitoneal injection of sodium pentobarbital ( $3 \mathrm{mg} / 100 \mathrm{~g}$ body weight). The anterior abdominal wall was opened $2 \mathrm{~cm}$ lateral to the spine, and WAT weighing from 3 to $7 \mathrm{~g}$ was collected from the abdominal cavity. The WAT was washed with Dulbecco's minimal essential medium (DMEM) containing $10 \%$ fetal bovine serum and $1 \%$ antibiotic/antimycotic (Gibco, Los Angeles, Calif., USA) two times to remove blood cells. After chopped into pieces, the WAT was digested with $10 \mathrm{ml}$ collagenase solution in a water bath at $37^{\circ} \mathrm{C}$ for 60 min under continuous shaking. To make the collagenase solution, $100 \mathrm{ml}$ of Hanks' balanced salt solution with calcium and magnesium (Sigma, St. Louis, Mo., USA), pH 7.4, containing $4 \mathrm{~g}$ of bovine albumin (fraction V), $300 \mathrm{mg}$ of collagenase type VIII $(40 \% \mathrm{am}$ monium sulfate fraction from Clostridium histolyticum, Sigma) and $1.3 \mathrm{mg} / \mathrm{ml}$ of glucose were sterilized using a $0.22-\mu \mathrm{m}$ filter. After collagenase treatment, the enzyme activity was neutralized with an equal volume of DMEM. The suspension was filtered through $250-\mu \mathrm{m}$ nylon mesh and centrifuged at $300 \mathrm{~g}$ for $5 \mathrm{~min}$ at room temperature to separate the pellet. The pellet was treated with red blood cell lysis buffer (Sigma) for $5 \mathrm{~min}$ at $37^{\circ} \mathrm{C}$, then filtered through a $100-\mu \mathrm{m}$ nylon mesh, followed by centrifugation ( $300 \mathrm{~g}$ for $5 \mathrm{~min}$ at room temperature) to obtain the pellet of ASCs (also referred to as the stromalvascular fraction). The cells were cultivated in $75 \mathrm{~cm}^{2}$ culture flasks, and the culture medium was changed twice a week. Upon reaching $60 \%-90 \%$ confluence, the ASCs were detached using 0.25\% trypsin-EDTA (Gibco), and divided 1:2. After 7 days in culture, the ASCs were isolated using trypsin, followed by centrifugation (300 g for $5 \mathrm{~min}$ at room temperature) to obtain a pellet of ASCs, which was then suspended in PBS to be autologously injected into the same recipient rats. The ASC suspension $\left(1.0 \times 10^{7} / 0.5 \mathrm{ml}\right)$ was gently infused within a few minuites via the external carotid vein of rats under local anesthesia. Control animals received the same volume of PBS.

\subsection{Experimental Groups}

The rats were randomly assigned to 6 weight-matched experimental groups. Group A included 7 animals that received intratracheal administration (IT) of bleomycin chloride solution (BLM) on day 0 , intravenous injection (IV) of $0.5 \mathrm{ml}$ phosphate buffer saline (PBS) via an external vein on day 14 , and were sacrificed on day 21 . Group B included 8 animals that received IT BLM on day 0 , had ASCs harvested on day 7, underwent IV of $1.0 \times 10^{7} \mathrm{ASC} / 0.5 \mathrm{ml} \mathrm{PBS}$ on day 14 , and were sacrificed on day 21. Group C included 7 animals that received IT saline on day 0 , IVPBS on day 14 , and were sacrificed day 21. Group D included 7 animals that received IT BLM on day 0 , IVPBS on day 14 , and were sacrificed on day 42. Group E included 6 animals that received IT BLM on day 0 , had ASCs harvested on day 7 , received IV of $1.0 \times 10^{7} \mathrm{ASC} / 0.5 \mathrm{ml}$ PBS on day 14 , and were sacrificed on day 42. Group F included 7 animals that received IT saline on day 0 , IVPBS on day 14 , and were sacrificed on day 42 .

\subsection{Dil and DAPI Staining}

For cell tracing, ASCs were labeled with CM-DiI (Invitrogen, Eugene, Oreg., USA) according to the manufacturer's protocol. Briefly, CM-DiI (in DMSO solution) was diluted in PBS to obtain a concentration of $10 \mu \mathrm{g} / \mathrm{ml}$. The ASCs were incubated with the dye solution for 3 min at $37^{\circ} \mathrm{C}$ followed by $15 \mathrm{~min}$ at $4^{\circ} \mathrm{C}$. The labeled ASCs were washed once with PBS, and then were cultured in DMEM as mentioned above at $37^{\circ} \mathrm{C}$ under $5 \%$ 
$\mathrm{CO}_{2}$ in humidified air. The labeling efficiency was confirmed to be greater than $90 \%$ by fluorescence microscopy. Nuclei were stained with DAPI (Sigma) on the glass slides.

\subsection{Bronchoalveolar Lavage (BAL)}

At 3 or 6 weeks after intratracheal administration of BLM, the rats were sacrificed by an intraperitoneal overdose injection of sodium pentobarbital. Immediately after the animals were killed, a 16-gauge cannula was inserted into the incised trachea. BAL was performed using $3 \mathrm{ml} \times 5$ infusions of $0.9 \%$ normal saline with withdrawal via the cannula. The cells in the BAL fluid were counted using a hemocytometer. Differential cell counts were performed using slides prepared by cytocentrifugation and May-Grünwald-Giemsa staining.

\subsection{Preparation of the Lung Tissues and Histological Evaluation by the SMI}

Following BAL, each left lung was inflated at a constant pressure of $20 \mathrm{~cm} \mathrm{H}_{2} \mathrm{O}$ of $10 \%$ paraformaldehyde for five minuites, removed from each animal, and fixed in $10 \%$ paraformaldehyde for several days. For the histological examination, each left rat lung was transversely sectioned into 7 pieces. The specimens were then dehydrated and embedded in paraffin. Four- $\mu \mathrm{m}$ thick sections were cut using a rotary microtome, placed on glass slides, deparaffinized, and sequentially stained with hematoxylin \& eosin and Masson's trichrome stains. Thereafter, the sections were examined using a standard light microscope (BX-40, Olympus, Tokyo, Japan). Among 6 independent cut planes, the three most severely injured were selected for a histological assessement by a semiquantitative morphological index (SMI) scaling, without knowledge of the treatment groups, using a grading scheme reported by Lossos et al. [17]. We used a fluorescence microscope (BZ-9000, Keyence, Tokyo, Japan) to examine the fluorescences, DiI and DAPI signals. The histological assessement by an SMI scaling was as follows: 0, normal lung; 1, minimal areas of inflammation, epithelial hyperplasia and fibrosis, usually limited to subpleural foci in just 1 or 2 sections; 2, more frequent lesions; 3 , all three sections exhibit lung lesions which are not limited to subpleural foci; 4, extensive lesions in at least 2 of 3 sections; 5 , the majority of each of the three lung sections are affected by inflammation and fibrosis.

\subsection{Statistical Analysis}

The data are expressed as the means \pm standard deviation. Upon detection of significant differences by the Kruskal-Wallis test, post-hoc pairwise comparisons were conducted using the Tukey-Kramer test, with the level of statistical significance set at $\mathrm{P}<0.05$.

\section{RESULTS}

\subsection{Total Cell Counts and the Profile in BALF (Figure 1)}

The total cell counts and cell profile in the BALF of groups $\mathrm{A}, \mathrm{B}$ and $\mathrm{C}$ were not significantly different. In addition, no significant differences in the total cell counts and cell profile in the BALF were observed among groups D, E and F. Moreover, there were no significant differences in the total cell counts between groups A and $\mathrm{D}$ or between groups B and $\mathrm{E}$. The number of neutrophils, lymphocytes, and macrophages in the BAL fluid of the ASC-treated rats in groups B and E were not significantly different from the PBS-treated rats in groups A and $\mathrm{D}$, respectively.

\subsection{Semiquantitative Morphological Evaluation of the Lung Injury in Rats Treated with ASC (Figure 2)}

The ASC-treated rats in groups B and E did not have significantly different scores compared to the PBStreated rats in groups A and D, respectively. A comparison of the histological changes between the rats in groups

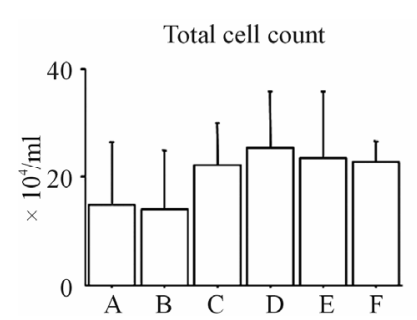

(a)

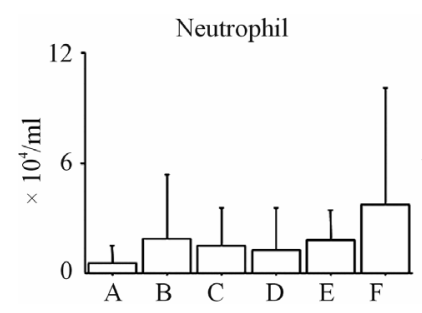

(c)

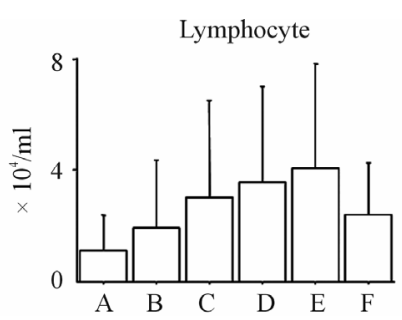

(b)

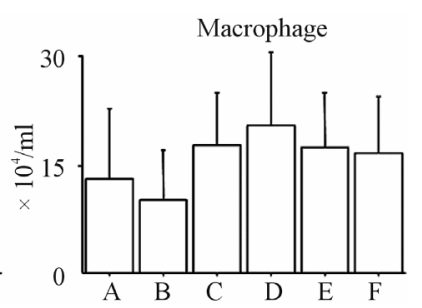

(d)
Figure 1. The time-dependent changes in the inflammatory cell profile in the BAL fluid the total cell count (a), lymphocyte counts (b), neutrophil counts (c), and macrophage counts (d) in the BAL fluid are shown. ASC treatment could not affect inflammatory cell counts following BLM-induced lung injury at 3 and 6 weeks after injury. No significant differences were found between any of the groups. Group A: BLM IT (day 0) + PBS IV (day 14) + sacrificed (day 21); Group B: BLM IT (day $0)+$ ASC harvest (day 7) + ASC IV (day 14) + sacrificed (day 21); Group C: Saline IT (day 0) + PBS IV (day 14) + sacrificed (day 21); Group D: BLM IT (day 0) + PBS IV (day 14) + sacrificed (day 42); Group E: BLM IT (day 0) + ASC harvest (day 7) + ASC ASC IV (day 14) + sacrificed (day 42); Group F: Saline IT (day 0) + PBS IV (day 14) + sacrificed (day 42). 


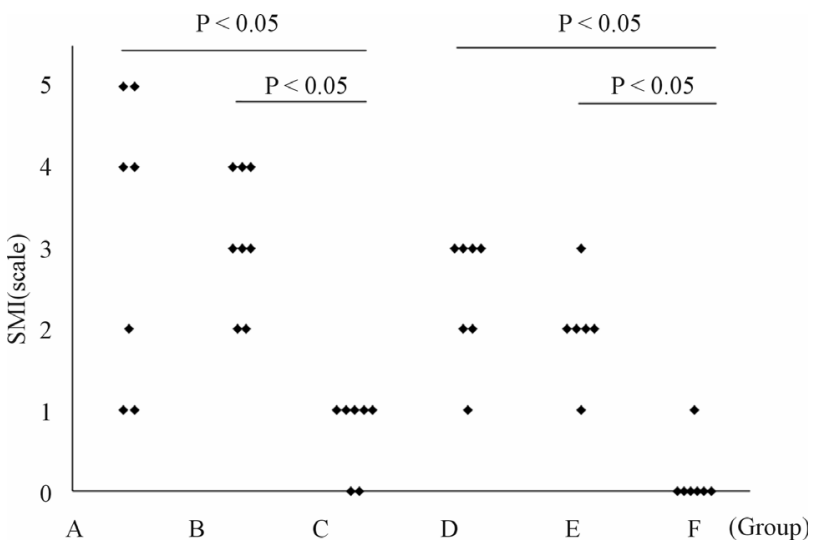

Figure 2. The BLM-induced histological changes in the lungs assessed by the SMI after ASC transfer. The ASC-treated rats in groups $\mathrm{B}$ and $\mathrm{E}$ did not have significantly different scores compared with PBS-treated rats in groups A and D, respectively. A comparison of the histological changes between groups $\mathrm{B}$ and $\mathrm{E}$, as well as between groups $\mathrm{A}$ and $\mathrm{D}$ revealed that there was temporal improvement in the natural course of BLM-induced lung injury. Group A: BLM IT (day 0) + PBS IV (day 14) + sacrificed (day 21); Group B: BLM IT (day 0) + ASC harvest (day 7) + ASC IV (day 14) + sacrificed (day 21); Group C: Saline IT (day 0) + PBS IV (day 14) + sacrificed (day 21); Group D: BLM IT (day 0) +PBS IV (day 14) + sacrificed (day 42); Group E: BLM IT (day 0) + ASC harvest (day 7) + ASC IV (day 14) + sacrificed (day 42); Group F: Saline IT (day 0) + PBS IV (day 14) + sacrificed (day 42).

$\mathrm{B}$ and $\mathrm{E}$, as well as between those in groups $\mathrm{A}$ and $\mathrm{D}$ revealed that there may be a temporal improvement in the bleomycin-induced lung injury.

\subsection{Distribution of Dil-Labeled ASCs in the Lung Fields (Figure 3)}

The ASCs were found in the BLM-injured lung field. However, some ASCs were present in the surrounding fibrotic areas and did not migrate into the scar (a representative photo is shown in Figure 3). Dil-labeled ASCs, fluoresced red, are emphasized by arrows. Nuclei labeled with 4',6-diamidino-2-phenylindole (DAPI) fluoresce blue.

\section{DISCCUSION}

In the present study, ASCs harvested from abdominal white adipose tissues could not reduce the severity of the bleomycin-induced lung injury in male rats. Many authors have reported benefits from using BMMSC for bleomycin-induced lung injury (Table 1) [10-13]. There are several possible explanations for this failure.

First, the ASCs in the present study were isolated and cultured using methods that have been proven to be effective [18-21]. Therefore, the number of cells used for intravenous transplantation is a very important quantity. The efficacy of using different total stromal cell counts

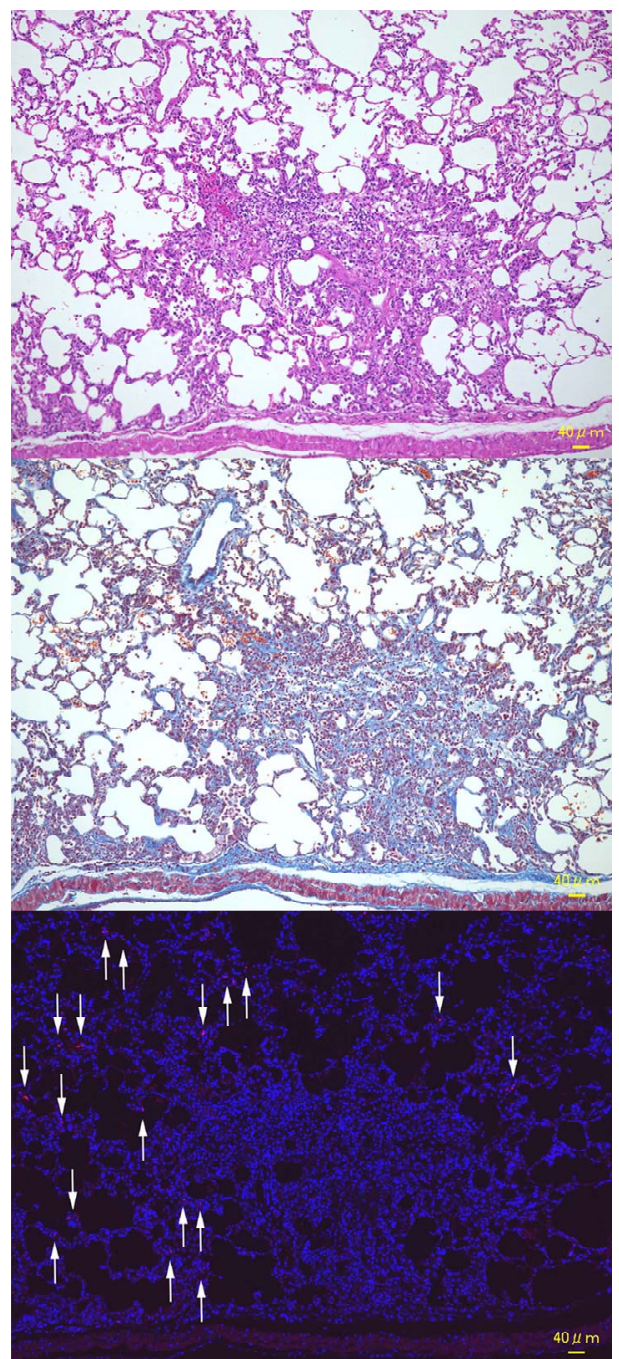

Figure 3. The ASCs surrounded the fibrotic tissue and did not migrate into the scar. The upper panel shows the results of hematoxylin \& eosin staining, middle panel shows the Masson's trichrome staining, and the lower panel shows the fluorescence. Nuclei were labeled with DAPI, and fluoresced blue. DiI-labeled ASCs (red fluoresence, indicated by arrows) surrounded the fibrotic tissue, but barely migrated into the scar, in which interstitium was thickened by fibrosis, and the alveolar architecture was distorted (a representative photograph is shown).

has been previously documented in various reports (Table 1). Since the stromal cell count per body weight in our study was similar to that used in many of the previous reports, the cell count was still suitable for stromal cell therapy. Therefore, we do not believe that the cell count was the major cause of the lack of efficacy.

Patients with IPF are often middle aged, usually between 40 and 70 years of age [1]. The incidence of the disease increases with older age. The rats used in our 
Table 1. The effects of intravenous MSC administration on bleomycin-induced lung injury.

\begin{tabular}{ccccccccc}
\hline Author (Ref) & Animal model & Period & Cell type & Passage & Num & Animal weight & Num/weight (kg) & Outcome \\
\hline Lee (10) & 6-wk female SD rats & 4 days & BMMSC & ND & $1 \times 10^{7}$ & ND *250 gram & $4 \times 10^{7}$ & effective \\
Zhao (11) & 4-wk male SD rats & 12 hours & BMMSC & 3 to 10 & $5 \times 10^{6}$ & $200-250$ gram & $2-2.5 \times 10^{7}$ & effective \\
Ortiz (12) & 6 - 10 wk female C57BL/6 mice 0 or 7 days & BMMSC & ND & $5 \times 10^{5}$ & ND *20 gram & $2.5 \times 10^{7}$ & effective \\
Rojas (13) & 6 - 8 wk C57BL/6 mice & 6 hours & BMMSC & ND & $5 \times 10^{5}$ & ND *20 gram & $2.5 \times 10^{7}$ & effective \\
Present & over 24-wk male Wister rats & 14 days & ASC & 0 to 1 & $1 \times 10^{7}$ & $370-540$ gram & $1.9-2.7 \times 10^{7}$ & ineffective \\
\hline
\end{tabular}

Ref: reference; Period: the duration from bleomycin instillation to cell therapy; Num: Number of cells; wk: week old; SD: Sprague-Dawley; BMMSC: bone marrow-derived mesenchymal stromal cell; ASC: adipose-derived stromal cell; ND: no data included in the report; ${ }^{*}$ : likely body weight based on animal age.

study were over the age of 24 weeks, which was relatively older than the rodents used in previous reports (Table 1). Many authors have shown the BMMSCs activities to decrease in older humans or animals [22-25]. Alt et al. isolated human ASCs from young, middle aged, and aged healthy volunteers, and demonstrated that the number of growing adherent cells/gram of adipose tissue was reduced with age, and their ability to form colonies was decreased, despite the identical expression of surface markers characteristic of ASCs [26]. Moreover, aging decreases the multi-lineage differentiation potential, and proliferative capacity in association with increases in cellular senescence, and significantly increased the quiescence of G2 and S phase in the cell cycle. The older animals used in the present study may therefore be one of the reasons for the failure of stromal cell therapy.

More males have been reported with IPF than females [1]. Recent studies have addressed gender differences in the pro- and anti-inflammatory properties of MSCs [27, 28]. For example, Crisostomo et al. have demonstrated gender differences in apoptosis and vascular endothelial growth factor, tumor necrosis factor, and interleukin-6 expression under lipopolysaccharide- and hypoxia-induced stress in murine BMMSC [27]. Since only male rats were used in the present study, we could not conclude whether the gender of the rats affected the outcome of therapy, but this is a possibility that should be examined in future studies.

With regard to cell transplantation into the lungs, some authors have investigated the survival rate of intravenously administerd MSCs, and found high percentages [29-31]. Because the duration from MSC injection to estimation of the cell counts in these studies was much shorter than the 3 and 6 weeks used in our study, our cell survival rate cannot be directly compared with the previous reports. A longer observation for stromal cell survival in vivo is needed to confirm the viability of cells following administraion.

It has been suggested that with increasing time in cell culture, and with increasing passages, cultured MSCs lose their proliferation and differentiation potential, and senesce [32,33]. As the cell passage number used in the present study was low, this was not one of the causes of treatment failure.

The intratracheal administration of bleomycin is a documented method for inducing pulmonary fibrosis in rodents. Thrall et al. reported time-dependent changes in the lung histopathology following intratracheal instillation of bleomycin in rats [34]. Within the first 3 to 5 days, focal areas of intraalveolar hemorrhage were present. Over the course of the first week, these changes gave way to the appearance of atypical alveolar lining cells and confluent interstitial inflammatory cell invasion. By the second week, the interstitial infiltrates were obviously associated with an increase in fibroblasts and the start of deposition of interstitial extracellular collagen. From the third week after instillation, the amount of collagen in the interstitial areas became increasingly prominent, with some evident condensation. In the previous studies that documented successful BMMSC treatment [10-13], therapy was initiated within hours or within one week after bleomycin instillation. However, in the present study, the stromal cell treatment was initiated two weeks after bleomycin administration when the fibroblasts had already started to appear and interstitial extracellular collagen had started to be deposited.

Okada et al. examined the effects of neural stem/progenitor cells (NSPCs) transplantation for spinal cord injury during both the acute and delayed phases in mice [35]. In the acute group, the NSPCs were mainly distributed within the scar area, while in the delayed group, the NSPCs were found around the scar. The timing of cell transplantation may therefore be a key determinant of the fates and function of integrated cells, since cell survival and migration depended on the time of transplantation relative to injury. Although the ASCs were noted to home to the lesion sites in our study, they accumulated around the scar and only scarcely migrated into fibrotic areas (Figure 3). Taken together, these findings indicate that it would not be likely that the ASCs surrounding the fibrotic tissue would secrete factors in a paracrine fashion to affect the inflammation and fibrosis. Instead, it ap- 
pears that the ASCs could not sufficiently migrate into the fibrotic areas in order to inhibit increasing interstitial fibrosis when they were administered from two to three weeks after bleomycin instillation. The precise mechanism responsible for the lack of migration into fibrotic areas is not clear. Baek et al. indicated that prior in vitro modulation by several chemokines or growth factors affected the homing capacity of human ASCs by changing the expression of receptors, and that this could stimulate the movement of the ASCs into injured areas in vivo when they were administered intravenously, thereby improving their therapeutic potential [36].

\section{CONCLUSION}

In our present study, the intravenous administration of ASCs could not reduce the severity of bleomycin-induced lung injury in rats. Although the stromal cell counts and passage number were suitable, the older age and fibrotic disease stage of the rats used in this study were likely responsible for the treatment failure.

\section{REFERENCES}

[1] Talmadge, E., King, J., Costabel, U., Cordier, J.-F., DoPico, G.A., Bois, R.M.D. and Lynch, D. (2000) American Thoracic Society. Idiopathic pulmonary fibrosis: Diagnosis and treatment. International consensus statement. American Thoracic Society (ATS), and the European Respiratory Society (ERS). American Journal of Respiratory and Critical Care Medicine, 161, 646-664. doi:10.1164/ajrccm.161.2.ats3-00

[2] Raghu, G., Collard, H.R., Egan, J.J., Martinez, F.J., Behr, J. and Brown, K.K. (2011) An official ATS/ERS/JRS/ ALAT statement: Idiopathic pulmonary fibrosis: Evidencebased guidelines for diagnosis and management. American Journal of Respiratory and Critical Care Medicine, 183, 788-824. doi:10.1164/rccm.2009-040GL

[3] Selman, M. and Pardo, A. (2004) Idiopathic pulmonary fibrosis: Misunderstandings between epithelial cells and fibroblasts? Sarcoidosis, Vasculitis, and Diffuse Lung Diseases, 21, 165-172.

[4] Selman, M., King, T.E. and Pardo, A. (2001) Idiopathic pulmonary fibrosis: Prevailing and evolving hypotheses about its pathogenesis and implications for therapy. Annals of Internal Medicine, 134, 136-151.

[5] Bouros, D. and Antoniou, K.M. (2005) Current and future therapeutic approaches in idiopathic pulmonary fibrosis. European Respiratory Journal, 26, 693-702. doi:10.1183/09031936.05.00145004

[6] Anstrom, K.J., Kaner, R.J., Loyd, J.E., Roman, J., Brown, K.K. and Kaner, R.J. (2010) The IPFnet strategy: Creating a comprehensive approach in the treatment of idiopathic pulmonary fibrosis. American Journal of Respiratory and Critical Care Medicine, 181, 527-528. doi:10.1164/rccm.200903-0483ED

[7] Hare, J.M., Traverse, J.H., Henry, T.D., Dib, N., Strumpf,
R.K. and Schulman, S.P. (2009) A randomized, doubleblind, placebo-controlled, dose-escalation study of intravenous adult human mesenchymal stem cells (prochymal) after acute myocardial infarction. Journal of the American College of Cardiology, 54, 2277-2286.

doi:10.1016/i.jacc.2009.06.055

[8] Stripp, B.R. and Shapiro, S.D. (2006) Stem cells in lung disease, repair, and the potential for therapeutic interventions: State-of-the-art and future challenges. American Journal of Respiratory Cell and Molecular Biology, 34, 517-518. doi:10.1165/rcmb.F315

[9] Prockop, D.J. (1997) Marrow stromal cells as stem cells for nonhematopoietic tissues. Science, 276, 71-74. doi:10.1126/science.276.5309.71

[10] Lee, S.H., Jang, A.S., Kim, Y.E., Cha, J.Y., Kim, T.H. and Jung, S. (2010) Modulation of cytokine and nitric oxide by mesenchymal stem cell transfer in lung injury/fibrosis. Respiratory Research, 11, 16. doi:10.1186/1465-9921-11-16

[11] Zhao, F., Zhang, Y.F., Liu, Y.G., Zhou, J.J., Li, Z.K. and Wu, C.G. (2008) Therapeutic effects of bone marrow-derived mesenchymal stem cells engraftment on bleomycininduced lung injury in rats. Transplantation Proceedings, 40, 1700-1705. doi:10.1016/j.transproceed.2008.01.080

[12] Ortiz, L.A., Gambelli, F., McBride, C., Gaupp, D., Baddoo, M. and Kaminski, N. (2003) Mesenchymal stem cell engraftment in lung is enhanced in response to bleomycin exposure and ameliorates its fibrotic effects. Proceedings of the National Academy of Sciences of the United States of America, 100, 8407-8411. doi:10.1073/pnas.1432929100

[13] Rojas, M., Xu, J., Woods, C.R., Mora, A.L., Spears, W. and Roman, J. (2005) Bone marrow-derived mesenchymal stem cells in repair of the injured lung. American Journal of Respiratory Cell and Molecular Biology, 33, 145-152. doi:10.1165/rcmb.2004-0330OC

[14] Cao, Y., Sun, Z., Liao, L., Meng, Y., Han, Q. and Zhao, R.C. (2005) Human adipose tissue-derived stem cells differentiate into endothelial cells in vitro and improve postnatal neovascularization in vivo. Biochemical and Biophysical Research Communications, 332, 370-379. doi:10.1016/j.bbrc.2005.04.135

[15] Rehman, J., Traktuev, D., Li, J., Merfeld-Clauss, S., TemmGrove, C.J. and Bovenkerk, J.E. (2004) Secretion of angiogenic and antiapoptotic factors by human adipose stromal cells. Circulation, 109, 1292-1298. doi:10.1161/01.CIR.0000121425.42966.F1

[16] Nakagami, H., Maeda, K., Morishita, R., Iguchi, S., Nishikawa, T. and Takami, Y. (2005) Novel autologous cell therapy in ischemic limb disease through growth factor secretion by cultured adipose tissue-derived stromal cells. Arteriosclerosis, Thrombosis, and Vascular Biology, 25, 2542-2547. doi:10.1161/01.ATV.0000190701.92007.6d

[17] Lossos, I.S., Izbicki, G., Or, R., Goldstein, R.H. and Breuer, R. (2000) The effect of suramin on bleomycin-induced lung injury. Life Sciences, 67, 2873-2881. doi:10.1016/S0024-3205(00)00865-1

[18] Tholpady, S.S., Katz, A.J. and Ogle, R.C. (2003) Mesenchymal stem cells from rat visceral fat exhibit multipo- 
tential differentiation in vitro. Anatomical Record Part A: Discoveries in Molecular, Cellular, and Evolutionary Biology, 272, 398-402. doi:10.1002/ar.a.10039

[19] Yoshimura, K., Shigeura, T., Matsumoto, D., Sato, T., Takaki, Y. and Aiba-Kojima, E. (2006) Characterization of freshly isolated and cultured cells derived from the fatty and fluid portions of liposuction aspirates. Journal of Cellular Physiology, 208, 64-76. doi:10.1002/jep.20636

[20] Kingham, P.J., Kalbermatten, D.F., Mahay, D., Armstrong, S.J., Wiberg, M. and Terenghi, G. (2007) Adipose-derived stem cells differentiate into a Schwann cell phenotype and promote neurite outgrowth in vitro. Experimental Neurology, 207, 267-274.

doi:10.1016/j.expneurol.2007.06.029

[21] Yoshimura, H., Muneta, T., Nimura, A., Yokoyama, A., Koga, H. and Sekiya, I. (2007) Comparison of rat mesenchymal stem cells derived from bone marrow, synovium, periosteum, adipose tissue, and muscle. Cell and Tissue Research, 327, 449-462. doi:10.1007/s00441-006-0308-Z

[22] Lee, C.C., Ye, F. and Tarantal, A.F. (2006) Comparison of growth and differentiation of fetal and adult rhesus monkey mesenchymal stem cells. Stem Cells and Development, 15, 209-220. doi:10.1089/scd.2006.15.209

[23] Mareschi, K., Ferrero, I., Rustichelli, D., Aschero, S., Gammaitoni, L. and Aglietta, M. (2006) Expansion of mesenchymal stem cells isolated from pediatric and adult donor bone marrow. Journal of Cellular Biochemistry, 97, 744754. doi: $10.1002 /$ icb. 20681

[24] Yue, B., Lu, B., Dai, K.R., Zhang, X.L., Yu, C.F. and Lou, J.R. (2005) BMP2 gene therapy on the repair of bone defects of aged rats. Calcified Tissue International, 77, 395403. doi:10.1007/s00223-005-0180-y

[25] Zhou, S., Greenberger, J.S., Epperly, M.W., Goff, J.P., Adler, C. and Leboff, M.S. (2008) Age-related intrinsic changes in human bone-marrow-derived mesenchymal stem cells and their differentiation to osteoblasts. Aging Cell, 7, 335-343. doi:10.1111/j.1474-9726.2008.00377.x

[26] Alt, E.U., Senst, C., Murthy, S.N., Slakey, D.P., Dupin, C.L. and Chaffin, A.E. (2012) Aging alters tissue resident mesenchymal stem cell properties. Stem Cell Research, 8 , 215-225. doi:10.1016/j.scr.2011.11.002

[27] Crisostomo, P.R., Wang, M., Herring, C.M., Markel, T.A., Meldrum, K.K. and Lillemoe, K.D. (2007) Gender differences in injury induced mesenchymal stem cell apoptosis and VEGF, TNF, IL-6 expression: Role of the 55 $\mathrm{kDa}$ TNF receptor (TNFR1). Journal of Molecular and Cellular Cardiology, 42, 142-149. doi:10.1016/j.yimcc.2006.09.016

[28] Hong, L., Sultana, H., Paulius, K. and Zhang, G. (2009) Steroid regulation of proliferation and osteogenic differentiation of bone marrow stromal cells: A gender difference. Journal of Steroid Biochemistry and Molecular Biology, 114, 180-185. doi:10.1016/j.jsbmb.2009.02.001

[29] Fischer, U.M., Harting, M.T., Jimenez, F., Monzon-Posadas, W.O., Xue, H. and Savitz, S.I. (2009) Pulmonary passage is a major obstacle for intravenous stem cell delivery: The pulmonary first-pass effect. Stem Cells and Development, 18, 683-692. doi:10.1089/scd.2008.0253

[30] Takasaki, Y., Watanabe, M., Yukawa, H., Sabarudin, A., Inagaki, K. and Kaji, N. (2011) Estimation of the distribution of intravenously injected adipose tissue-derived stem cells labeled with quantum dots in mice organs through the determination of their metallic components by ICPMS. Analytical Chemistry, 83, 8252-8258. doi:10.1021/ac202053y

[31] Schrepfer, S., Deuse, T., Reichenspurner, H., Fischbein, M.P., Robbins, R.C. and Pelletier, M.P. (2007) Stem cell transplantation: The lung barrier. Transplantation Proceedings, 39, 573-576.

doi:10.1016/j.transproceed.2006.12.019

[32] Derubeis, A.R. and Cancedda, R. (2004) Bone marrow stromal cells (BMSCs) in bone engineering: Limitations and recent advances. Annals of Biomedical Engineering, 32, 160-165. doi:10.1023/B:ABME.0000007800.89194.95

[33] Crisostomo, P.R., Wang, M., Wairiuko, G.M., Morrell, E.D., Terrell, A.M. and Seshadri, P. (2006) High passage number of stem cells adversely affects stem cell activation and myocardial protection. Shock, 26, 575-580. doi:10.1097/01.shk.0000235087.45798.93

[34] Thrall, R.S., McCormick, J.R., Jack, R.M., McReynolds, R.A. and Ward, P.A. (1979) Bleomycin-induced pulmonary fibrosis in the rat: Inhibition by indomethacin. American Journal of Pathology, 95, 117-130.

[35] Okada, S., Ishii, K., Yamane, J., Iwanami, A., Ikegami, T. and Katoh, H. (2005) In vivo imaging of engrafted neural stem cells: Its application in evaluating the optimal timing of transplantation for spinal cord injury. FASEB Journal, 19, 1839-1841.

[36] Baek, S.J., Kang, S.K. and Ra, J.C. (2011) In vitro migration capacity of human adipose tissue-derived mesenchymal stem cells reflects their expression of receptors for chemokines and growth factors. Experimental and $\mathrm{Mo}$ lecular Medicine, 43, 596-603.

doi:10.3858/emm.2011.43.10.069 